\title{
Kalibrasi Program Kerja Tarbiyah, Dakwah dan Financial Statement Berbasis Kemasjidan
}

\author{
${ }^{1 *}$ Rasfiuddin Sabaruddin, ${ }^{2}$ Agus Suprayogi, ${ }^{3}$ Muhammad Saddam, ${ }^{4}$ Herman Rustandi, \\ ${ }^{5}$ Nurjaya \\ 1.2.3.4STIE Hidayatullah Depok, Depok, Jawa Barat, Indonesia \\ ${ }^{5}$ Universitas Suryakancana, Cianjur, Jawa barat, Indonesia \\ *rasfiuddin.sabaruddin@stiehidayatullah.ac.id
}

\begin{abstract}
Abstrak
Pengabdian Kepada Masyarakat (PKM) adalah suatu kegiatan intrakurikuler yang memadukan pelaksanaan tri darma perguruan tinggi (Pendidikan, penelitian, dan pengabdian kepada masyarakat) dengan cara menerbitkan kepada mahasiswa pengalaman belajar dan bekerja dalam kegiatan pembangunan masyarakat sebagai wahana penerapan dan perkembangan ilmu dan teknologi yang dilaksanakan di luar kampus dalam waktu mekanisme kerja dan teknologi persyaratan tertentu. Tujuan utama dalam kegiatan ini sebagai pemenuhan dan pelaksanaan tri dharma perguruan tinggi yang harus dijalankan oleh setiap civitas academik perguruan tinggi. PKM yang beretempat di Masjid alkaustar cluster anggrek 2 Grand Depok City, dengan mengusung tema kalibrasi program kerja tarbiyah, dakwah dan keuangan berbasis kemasjidan. Perencanan program yang berkerjasama dengan pengurus masjid setempat sehingga program ini bisa dijalankan sesuai harapan. Meskipun hasil pembahasan dan pelaksanaan masih kurang maksimal karena kegiatan ini dilaksanakan masi dalam kondisi pandemic 19.
\end{abstract}

Kata Kunci: Tarbiyah, dakwah, dan financial statement

\begin{abstract}
Devotion to social community (PKM) is an extracurricular activity that combines the implementation of Tridharma of higher education (education, research, and community service) by giving students experience of learning and working in community development as a medium to implement and to develop science and technology off-campus in a specific time, work mechanism, and technology available. The main objective of PKM is to fulfil and to implement higher education Tridharma compulsory for every university. PKM that is conducted in Masjid Al-Kautsar Anggrek 2 Cluster, Grand Depok City, brought the theme of mosque-based tarbiyyah, da'wah, and financial management program calibration. This program planning has been cooperated with the administration of the mosque, thus resulted the program conducted according to its planning, although the result of the discussion and its implementation is not at its best fulfilment due to the situation of Covid-19 pandemic.
\end{abstract}

Keyword: Tarbiyah, da'wah, financial statement

\section{PENDAHULUAN}

Bidang ekonomi, Pendidikan dan dakwah menjadi inovasi dan potensi lokal yang berkehendak diberdayakan adalah produk usaha kecil bersama-sama antara mahasiswa kuliah kerja nyata dengan masyarakat sekitar lokasi kuliah kerja nyata. Hal tersebut sesuai dengan prinsip kuliah kerja nyata tematik.

PKM adalah kegiatan yang memiliki hubungan dengan berbagai disiplin ilmu. Pendekatan yang digunakan adalah pendekatan interdisipliner dan lintas sectoral. Kegiatan dan pengelolaan PKM ini dapat menjamin diperolehnya pengalaman belajar melakukan kegiatan pembangunan masyarakat secara kongkrit yang bermanfaat bagi civitas akademik dan masyarkat dimana kegiatan ini dilaksanakan. Selain itu, kegiatan dan pengelolaan PKM diarahkan untuk menjamin keterkaitan antara dunia akademik teoritik dan dunia empirik.

\section{METODE}

Metode pelaksanaan pengabdian kepada masyarakat ini diawali dengan melakukan observasi lapangan dan koordinasi dengan mitra. Metode kegiatan ini adalah mendatangi dan 
melaksanakan kegiatan yang berkaitan dengan tarbiyah, dakwah dan financial statement berbasis kemasjidan yang langsung diraskan oleh masyarakat sekitar.

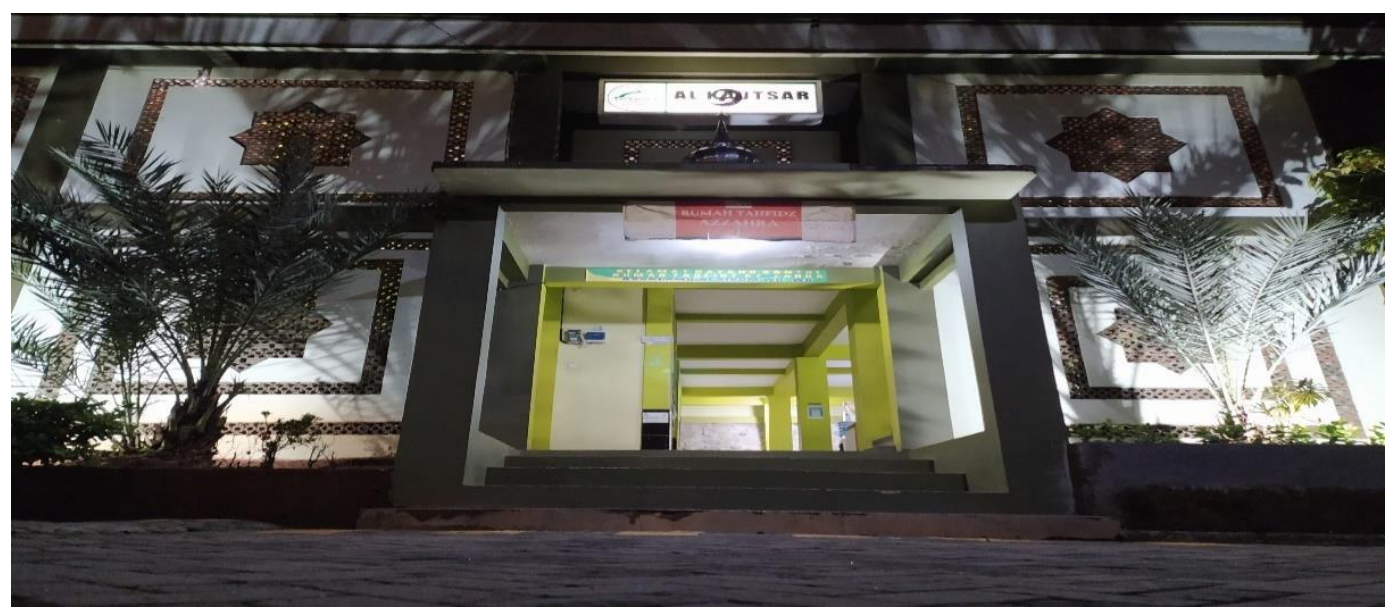

Gambar 1. Masjid alkutsar Anggrek 2 Grand Depok City Gambar diatas adalah objek kegiatan PKM.

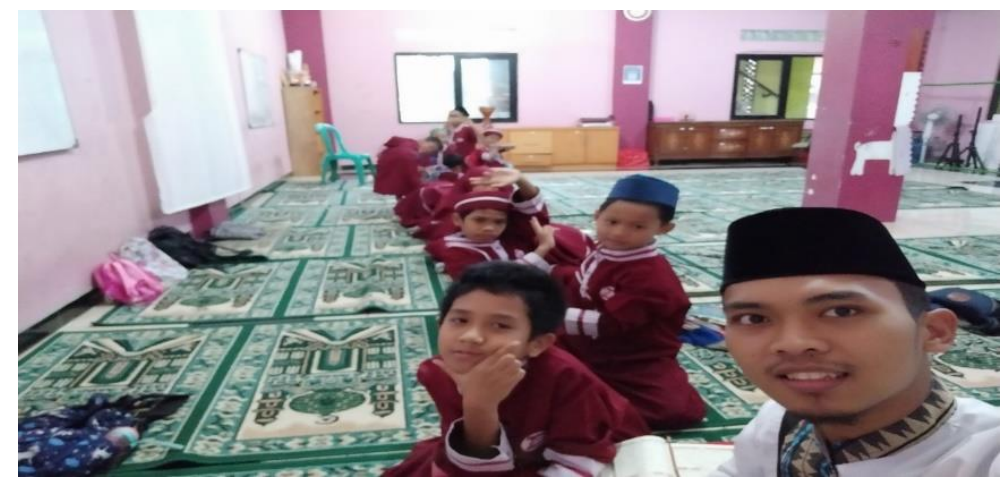

Gambar 2. Pelaksanaan Kegiatan (Tarbiyah) PKM dilokasi

Gambar di atas merupakan kegiatan mengajar mengaji untuk rumah tahfidz az zahra cluster anggrek 2 grand depok city. Hal ini dilakukan sebagai bentuk pendidikan atau tarbiyah serta pengkaderan kepada anak-anak warga yang berada di lingkungan anggrek 2 grand depok city.

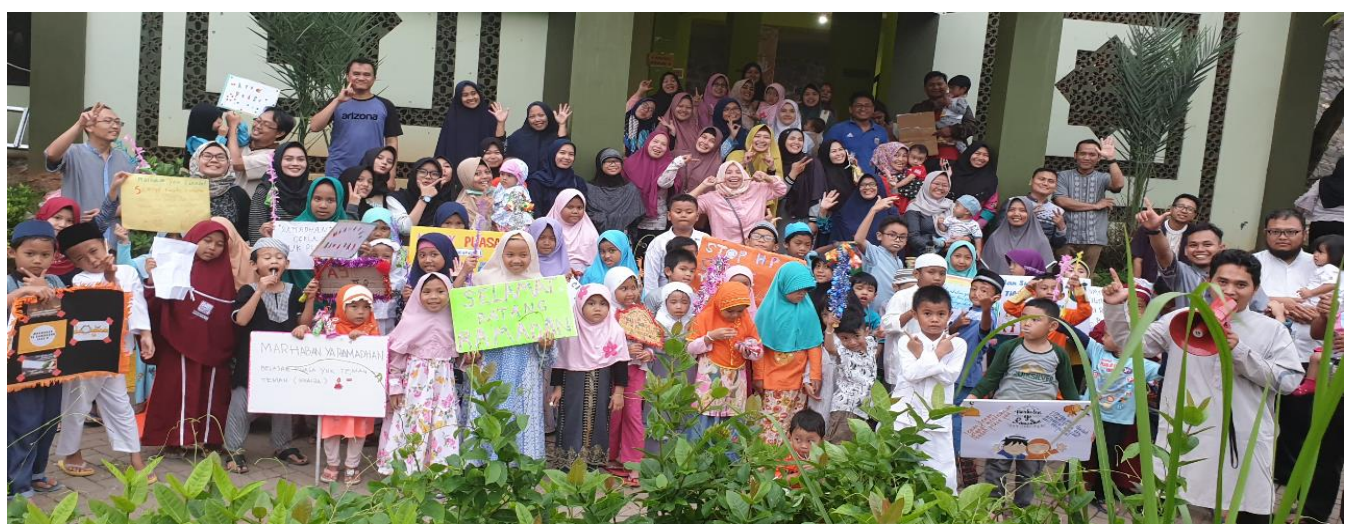

Gambar 3. Gambar pasca kegiatan kajian bulanan disaat zona hijau 
Gambar tersebut pasca kajian bulanan seluruh lapisan warga anggrek 2 yang dilaksanakan satu kali satu bulan yaitu pada hari ahad pekan ke 4, kegiatan ini adalah implementasi kegiatan dakwah di masjid Alkautsar yang bertujua untuk melakukan pembinaan kepada seluruh lapisan masyarakat yang ada diwilayah tersebut. Kegiatan ini dilaksanakan secara langsung pada saat wilayah tersebut masi dalam situasi zona hijau. Setelah kasus pandemic (Covid 19) semakin menigkat kajian dilaksanakan secara virtual melalui zoom meeting.

\section{HASIL DAN PEMBAHASAN}

Populasi Muslim di Indonesia adalah yang terbanyak di dunia. Data World Population Review pada 2020 mencatat populasi Muslim di Tanah Air mencapai 229 juta jiwa atau membentuk 87,2 persen dari total penduduknya yang sebanyak 273,5 juta jiwa. Tentu populasi muslim tersebut berpengaruh dengan jumlah masjid yang ada di Indonesia sebagai tempat ibadah kaum Muslim. SIMAS (Sistem Informasi Masjid) Kemenag RI, menyebutkan bahwa jumlah masjid dan mushala di Indonesia seluruhnya ada sebanyak 741.991. Data ini merupakan data yang tercatat manual yang diperoleh secara berjenjang mulai dari Kantor Urusan Agama di tiap daerah. Sementara.

Yang menjadi perhatian pada PKM ini dari sekian banyak masjid yang ada di Indonesia tidak semua memiliki program yang terstandar khususnya pada bidang tarbiyah, dakwah dan laporan keuangan. Kemudian yang sudah merancanakan program belum semuanya terlaksana sebagaiman yang diharapkan. Oleh sebab itu PKM ini diharapkan bisa sedikit berkontribusi dalam mensukseskan kegiatan kemasjidan pada bidang tarbiyah, dakwah dan financial statement khususnya di Masjid alkaustar cluster anggrek 2 Grand Depok City.

Sentuhan akademisi memberi pencerahan dan sudut pandang yang luas kepada pengurus dan masyarakat sekitar. Dengan adanya kegiatan PKM ini memberi dorongan kepada pengurus masjid Masjid alkaustar cluster anggrek 2 Grand Depok City, untuk mengetahui lebih banyak manfaat kegiatan tarbiyah, dakwah dan financial statement, karena pada pelaksanaan kegiatan PKM ini Tim STIE Hidayatullah Depok mendapati beberapa permasalahan yang sedang terjadi di masjid ini:

1. Kegiatan Tarbiyah serta pengkaderan bagi jamaah dan remaja masjid alkautsar mengalami hambatan karena adanya pandemic covid 19.

2. Bidang dakwah yang diprogramkan oleh masing masing depatemen berjalan secara virtual namun kurang maksimal Ketika devaluasi secara langsung Ketika rapat virtual. Berbeda dengan kajian-kajian yang dilakukan secara tatap muka langsung.

3. Laporan keuangan yang disusun sesuai berbasis kemasjidan seharusnya disusun dan dilaporkan sesaui dengan PSAK 45 tentang penyusunan laporan keuangan organisasi nirlaba atau non corporate. Apabila mengacu pada SAK 45 tersebut masih jauh karena laporan yang disajikan masih standar.

Oleh sebab kendala di atas, kegiatan PKM ini memberikan dorongan dan saran berupa solusi kepada para pengurus masjid al kautsar agar semakin giat melaksanakan kegiatan tarbiyah yang juga menjadi program utama dalam pembinaan masyarakat khususnya pada jenjang anak-anak dan remaja, kemudian memupuk semangat para pengurus dan jama'ah masjid untuk melaksanakan kegiatan dakwah yang diwakili oleh kajian rutin bulanan yang menyasar seluruh lapisan masyarakat sekitar yang bertujuan melakukan pembinaan keagamman secara berkala. Meskipun dalam kondisi pandemi seperti ini kegiatan tersebut tetap berjalan meskipun dengan online. 


\section{PENUTUP}

\section{KESIMPULAN}

Sebaiknya seluruh pengurus masjid alkautsar memberikan perhatian khusus kepada program yang sudah berjalan, agar kegiatan tersebut terus berkesinambungan, dan tentunya pada masa pademi ini para pengelolah diharapkan mampu menawarkan program kemasjidan yang menarik dan tetap menjaga dan menaati protocol Kesehatan, sehinga jamaah masjid alkautsar terus tercerhkan. Begitu pula sebaliknya, masyarakat diharap untuk bisa memberikan dukungan penuh terhadpat program kemasjidan yang telah berjalan.

\section{SARAN}

Berdasarkan bebrapa penjelasan yang telah diuraikan oleh penulis diatas, maka ada beberapa saran yang bisa diterapkan dalam tatakelola baik dalam manajemen program ataupun dalam manajemen pelaporan keuangan, diantaranya adalah:

1. Sekalipun dalam masa pandemic covid 19 semua program yang telah berjalan secara virtual baik kegiatan tarbiyah maupun dakwah bisa juga dilaksanakan secara tatap muka dengan mematuhi protokol kesehatan yang telah ditetapkan oleh pemerintah dan pengurus DKM.

2. Pelaporan keuangan yang dibuat secara berkala baik yang sifatnya bulanan ataupun yang sifanya tahunan, lebih efektif apabila menerapkan PSAK 45 tentang pelaporan keuangan organisasi nirlaba atau non corporate dengan menerapkan sesuai perilaku pencatatan akuntansinya.

\section{DAFTAR PUSTAKA}

Aidh Al Qarni, Mujtamaul Mutsul, Tarj. Masrukhin, Masyarakat Idaman, Depok: Pustaka Nauka, 2006, hal. 273

Bahrun Rifa'i dan Fakhrurrozi, Manajemen Masjid, Mengoptilmalkan Fungsi Sosial - Ekonomi Masjid, Bandung: Benang Merah Press, cet. 1, 2005, hal. 40

Bintari, W. C., et al.. (2019). Pelatihan Penyusunan Laporan Keuangan Secara Sederhana Pada Mahasiswa Fakultas Ekonomi Universitas Muhammadiyah Sorong. Abdimas: Papua Journal of Community Service, 1(2), 6-13.

https://www.ayopurwakarta.com/read/2021/03/29/7949/tahukah-berapa-jumlah-masjiddan-mushala-di-indonesia

Puji, Astari, Mengembalikan Fungsi Masjid sebagai Pusat Peradaban Masyarakat, (IAIN Raden Intan Lampung :Jurnal Ilmu Da"wah dan Pengembangan Komunitas, 2014), hlm. 34

Sidi Gazalba, Masjid Pusat Ibadah dan Kebudayaan Islam, Jakarta: pustaka antara, 1975, hlm. 320 338.

Suharsono, Membangun Peradaban Islam, Menata Indonesia Masa Depan dengan Al Qur'an, Jakarta: Inisiasi, 2011, hal. 151

Suwanto, S., et al. (2020). Menggali Potensi, Memotivasi Dan Mengarahkan Generasi Muda Menyongsong Dunia Kerja Pada PKBM Cipta Tunas Karya Cipondoh Kota Tangerang. Jurnal Pengabdian Dharma Laksana, 2(2), 132-136.

Syahidin, Pemberdayaan Umat Berbasis Masjid, Bandung: Alpabeda, 2004, hal. 130 